\title{
A Pilgrimage to the God Stone
}

\author{
J. Turnquist, Wallwort
}

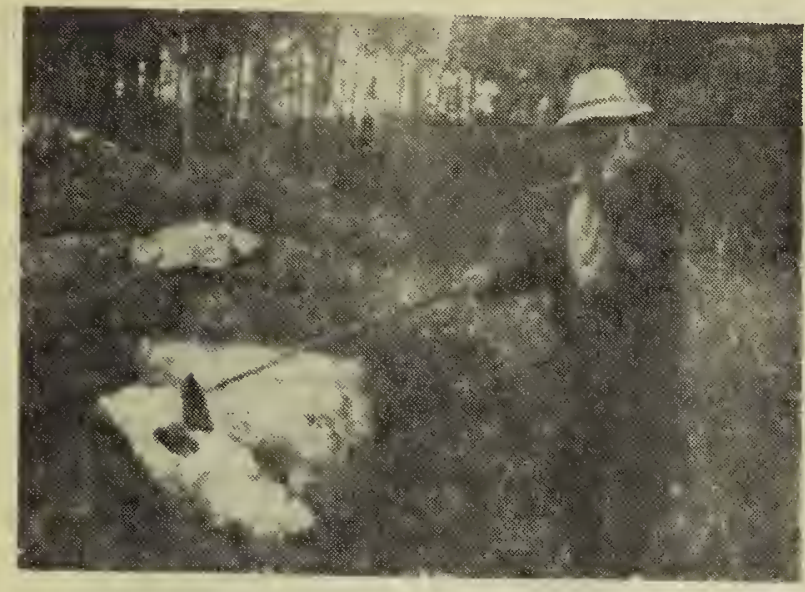

Early on the morning of the first of June my friend, Mr. Hunt, and I started out to see for ourselves the God Stone, of which we had heard so much.

The Stone's location is on the bank of the Red Deer River, about fifteen miles north-east of Archerwell, Sask., and on the old Indian trial from Nut Mountain to the Pasqua Hill counry

We met some of the people living in the vicinity and gathered some information from them. After taking off on foot a mile and a half we arrived at the stone. We found a large limestone, two and a. half paces long by two paces wide and about five feet of it out of the ground. It has a crack running all along it, with an opening of about two inches and several smaller cracks.

I had heard of this stone for some time and that the Indians left offerings here to the gods. Our visit proved to us that they still do, for we found some old clothing including a child's blouse, showing very little wear, old mits, a pair of rubbers and the remains

\section{Patience-(continued from page 15)}

I saw her once more, hopping in and out the crack at the bottom of the warped veranda door. Next day she did not return. Nor did I set out food for the others till they came seeking nourishment in stormy weather.

This year the chickadee came back in July from theirfar-pasture migration.

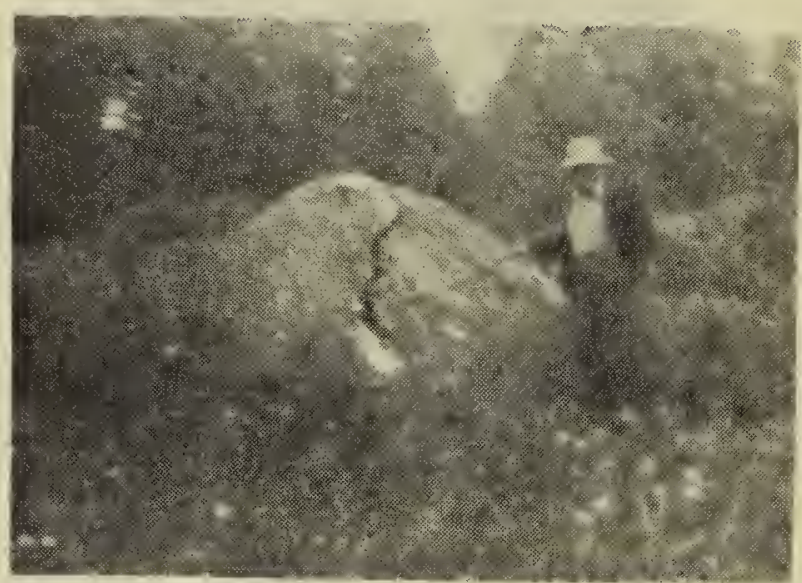

of tobacco, and cigarette paper wrappings, etc.

Locally it is believed that the Indians left offerings of money (coins) in the large crack of the Stone, and so there is danger that some passer-by may try to recover a dime or two from it. However I discounted that idea very much, for the Indian never was man of money.

There is neither writing not markings on the Stone, but the trail showed horse tracks and indicated that wagons had passed that way not long ago. The old trail is cut off in many places, and the site of the stone itself is in an out-of -the-way place. The river bank, close by, has a good spring. We found the river high and very swift, but were told that summer or fall it may be dry.

My friend and I left no offerings, but we took a couple of snaps one of the writer pointing to the crack in the stone - the other to the offerings, You will notice a pair of rubbers and directly above them the blouse, mentioned above.

Obviously they expected nuts, though all are more timid than Sweetheart was in demanding them. One small bird has much of her mother's engaging personality. Perhaps, if I do not tempt them indoors again they will remain wary of marauding cats; and to gain their trust will not be to betray it, as I feel I did before. 